\title{
Pesquisa em educação: confluências entre Didática, História e Antropologia ${ }^{1}$
}

\section{Research on education: necessary dialogues between Didactics, History and Anthropology}

\author{
Tânia Maria Figueiredo Braga Garcia²
}

\begin{abstract}
RESUMO
A produção de pesquisas sobre processos constitutivos da experiência escolar, em suas múltiplas dimensões, impõe a necessidade de debate permanente sobre as abordagens de investigação, seus limites e possibilidades. Pesquisas sobre o ensino, de forma particular, têm estimulado o debate sobre pressupostos e estratégias para a realização de trabalhos empíricos, a partir do diálogo com as Ciências Sociais. A presença das abordagens etnográficas, com diferentes perspectivas, evidencia a contribuição da Antropologia para a pesquisa educacional, pela incorporação de vários elementos às formas de produzir conhecimentos sobre a escola e a sala de aula. É preciso reconhecer as transformações produzidas pela incorporação do conceito de cultura, mas, ao mesmo tempo, é preciso apontar dificuldades em superar o caráter a-histórico desse conceito. Debates recentes apontam possibilidades de estabelecer relações mais estreitas entre Educação e Antropologia Histórica e, dessa forma, integrar a dimensão temporal nas pesquisas etnográficas que estudam processos atuais de escolarização, incluindo-se aqueles caracterizados particularmente como situações didáticas.

Palavras-chave: Pesquisa em educação; pesquisa etnográfica; educação histórica; relações entre educação e antropologia histórica; pesquisa em situações didáticas.
\end{abstract}

${ }^{1}$ Bolsa Produtividade em Pesquisa do Conselho Nacional de Desenvolvimento Científico e Tecnológico (CNPq).

${ }^{2}$ Doutora em Educação pela Universidade de São Paulo. Professora do Departamento de Teoria e Prática de Ensino e do Programa de Pós-Graduação em Educação, Setor de Educação da Universidade Federal do Paraná. e-mail: taniabraga@pq.cnpq.br 


\begin{abstract}
The production of research on constitutive processes of the school experience in its multiple dimensions imposes the necessity of permanent debate about the investigation approaches, their limits and possibilities. Research about teaching, particularly, have been stimulating the debate on presuppositions and strategies for the performance of empirical works, based on the dialogue with the social sciences. The presence of ethnographical approaches, although with different perspectives, evidences the contribution of anthropology to educational research, through the incorporation of several elements to the ways of producing knowledge about the school and the classroom. It is necessary to recognize the transformations produced by Brazilian educational research through the incorporation of the concept of culture; at the same time, it is necessary to point out the difficulties in overcoming the a-historical character of such concept. The recent debates indicate the possibilities of establishing closer relationships between education and historical anthropology, integrating the temporal dimension into the ethnographical research which study current schooling processes, including those characterized particularly as didactical situations.
\end{abstract}

Keywords: research on education; ethnography; historical education; relationships between education and historical anthropology; research on didactical situations.

\title{
Introdução
}

Nos últimos trinta anos, construiu-se entre investigadores de diversas comunidades acadêmicas um amplo consenso sobre abordagens que seriam mais adequadas ao estudo da escola e da sala de aula, particularmente quando a pesquisa focaliza as práticas escolares. Sustentadas teoricamente em diferentes "tradições", como sugerido por Jacob (1987), ou em diferentes "abordagens", como proposto por Atkinson, Delamont e Hammersley (1988), são inúmeras as possibilidades de investigação agrupadas, hoje, sob o rótulo de "pesquisa qualitativa" - expressão controversa, mas de utilização corrente nas Ciências Sociais e, em particular, na Educação.

Pode-se relembrar a afirmação de Hammersley (1992, p. 3) quanto à existência de "um certo clima de distensão", uma vez que investigadores "quantitativos" passam a admitir que a pesquisa "qualitativa" tem sua própria lógica, assim como seus próprios critérios de validade. Porém, para o autor, isso não deveria desencorajar debates sobre "importantes e negligenciadas questões metodológicas" nesse campo. 
Nessa direção, mantém-se atenção especial ao estudo das abordagens denominadas qualitativas no âmbito da Linha de Pesquisa Cultura, Escola e Ensino, do Programa de Pós-Graduação em Educação da Universidade Federal do Paraná. A produção de conhecimento sobre processos constitutivos da experiência escolar, em suas múltiplas dimensões, impõe a necessidade de debate permanente sobre o tema, na direção de compreender as diferentes alternativas, seus limites e possibilidades para diferentes objetos científicos.

A atuação como professora de seminários obrigatórios de pesquisa em nível de mestrado e doutorado e como membro de mais de uma centena de bancas de qualificação e defesa, ao longo da última década, propiciou fértil espaço teórico e empírico para o diálogo com uma diversidade de projetos de pesquisa; embora orientadas por distintas perspectivas teóricas e metodológicas, todas as investigações inserem-se em uma mesma linha de pesquisa cujos objetos dizem respeito a alguma dimensão específica da experiência escolar. Para além do estudo das políticas governamentais e das normas oficiais, isto significa uma intencionalidade de aproximação com o que se pode denominar como o "conteúdo da experiência escolar subjacente às formas de transmitir o conhecimento, à organização das atividades de ensino e às relações institucionais que sustentam o processo escolar." (ROCKWELL, 1995, p. 13).

As pesquisas sobre o ensino em certas áreas de conhecimento demandaram a revisão dos pressupostos e das estratégias para a realização de trabalhos empíricos, fortalecendo a presença da Sociologia e da Antropologia como fontes de teorias e métodos que permitem a aproximação desejada com a experiência escolar. Mas, por outro lado, evidenciaram a necessidade de tratar os processos de escolarização em sua temporalidade e, então, estabelecer relações mais estreitas entre a Educação e a História.

Uma primeira sistematização dessas discussões foi apresentada por Schmidt e Garcia (2008), na perspectiva de evidenciar as potencialidades de um diálogo entre os dois campos. Para as autoras, o estudo dos processos de escolarização, no contexto contemporâneo, não pode prescindir dos debates e de posicionamentos quanto às relações entre indivíduo e sociedade, questão central para a Teoria Social. Incorporando as contribuições derivadas das perspectivas que defendem a necessidade de compreensão das ações humanas pela análise de experiências singulares e, por outro lado, das perspectivas que insistem nas dimensões socioculturais do movimento histórico, as autoras defendem que:

As ações dos sujeitos em suas relações com as estruturas precisam ser vistas como realidades objetivas e absolutamente dialéticas, co-implicadas, mutuamente criativas e insubstituíveis na explicação da realidade escolar, 
perspectiva esta que indica a importância do diálogo interdisciplinar no interior da teoria social e aponta para a influência da História, da Antropologia e da Sociologia na própria metodologia da pesquisa educacional. (SCHMIDT; GARCIA, 2008, p. 31)

Especialmente para investigações em Educação Histórica, essa questão diz respeito ao esforço para se aproximar do pensamento histórico de crianças, jovens e adultos - por meio do qual presente, passado e futuro são articulados -, a partir das relações entre ensino e aprendizagem histórica e a formação da consciência histórica (RÜSEN, 1992).

Isso significa que, embora os estudos enfatizem o conhecimento histórico no âmbito escolar, levam em conta também a existência de uma cultura histórica, mais ampla, na qual a história escolar está inserida. (RÜSEN, 2001a; 2001b; 2007; MARTINS, 2010).

Em uma análise de caráter geral, segundo Garcia (2009), é preciso reconhecer as transformações produzidas na pesquisa educacional pela incorporação dos conceitos de cultura e de cotidiano - aproximação com os sujeitos, busca pelo significado das ações, uso da observação como estratégia de trabalho empírico, entre outras. Mas, ao mesmo tempo, deve-se apontar que novos desafios estão colocados aos pesquisadores que pretendem ir ao encontro dos professores e alunos, tanto com o compromisso da produção do conhecimento científico, quanto com a transformação da qualidade das experiências com o conhecimento, em escolas e salas de aula.

O ponto que se deseja focalizar, neste artigo, diz respeito a algumas implicações para a pesquisa quando se aceita que as apropriações - usos, práticas e concepções - realizadas na vida cotidiana só têm sentido quando examinadas na História - ou, nas palavras de Heller (2002, p. 159), que “[...] a cotidianidade não tem um 'sentido' autônomo. A cotidianidade somente ganha um sentido no contexto de outro meio, a história, no processo histórico como substância da sociedade"’3.

Ao mesmo tempo em que se admite o consenso em torno da adequação de abordagens qualitativas para pesquisar as práticas escolares - as etnográficas, em particular -, é preciso reconhecer os limites decorrentes das dificuldades de incorporação da temporalidade histórica nas análises, o que demanda novas sistematizações. Espera-se, então, apontar contribuições ao debate epistemológico e metodológico sobre a pesquisa no ensino, na aprendizagem e, de forma geral, para a pesquisa em Didática.

${ }^{3}$ Os textos da edição em espanhol foram aqui traduzidos livremente. 
Especialmente para a Didática na perspectiva da Educação Histórica, que objetiva uma aproximação com o pensamento histórico dos sujeitos - alunos e professores, no caso do conhecimento histórico ensinado e aprendido na escola -, este é um desafio que cobra a atenção dos pesquisadores. Com o intuito sistematizar reflexões sobre alternativas de pesquisa no campo do ensino, retomam-se elementos para situar de forma mais detalhada as contribuições da sociologia e da antropologia aos estudos na escola e na sala de aula e, ao final, apontam-se algumas questões de caráter epistemológico e metodológico, derivadas de uma abordagem multiperspectivada sobre a pesquisa que se realiza em escolas, em situações didáticas.

\section{A pesquisa educacional e a pesquisa na escola: aproximações com a So- ciologia e a Antropologia}

Um dos elementos fundamentais ao se discutir a pesquisa em educação é situar a complexidade desse campo, especialmente para destacar as múltiplas abordagens possíveis aos pesquisadores cujos objetos científicos estão situados nesse campo temático. A diversidade de situações educativas corresponde à necessidade de escolha pelo pesquisador do espaço teórico e metodológico no qual pretende inserir seus estudos. A educação informal e a educação formal, por exemplo, são situações educativas diferenciadas e exigem abordagens específicas que permitam captar suas especificidades.

Por outro lado, é preciso lembrar que cada uma das Ciências da Educação estabeleceu historicamente âmbitos diferenciados de produção de conhecimento, com objetivos próprios e, em consequência, com teorias e métodos específicos - embora sejam conhecidos também os esforços para encontrar domínios científicos articuladores ${ }^{4}$. Dessa forma, falar em metodologia de pesquisa educacional exige cuidados para circunscrever o espaço em que serão feitas as análises.

Quanto ao estudo das práticas escolares - objeto de reflexão neste artigo -, a opção pela pesquisa na escola e nas aulas tem cobrado do pesquisador a capacidade de dialogar intensamente com a Sociologia e a Antropologia, particularmente quando se define a experiência escolar a partir de suas conexões com a vida social. Pode-se dizer que é impossível compreender a pesquisa sobre determinados temas da experiência escolar sem examinar as confluências com tais disciplinas. Esse diálogo, restrito até a metade do século XX, foi fortalecido a partir do final da década de 1970.

${ }^{4}$ Conceito usado aqui no sentido apontado por Lloyd, a partir de Shapere, para "corpos temáticos que se delinearam do modo como as entidades, as forças e os sistemas do mundo têm sido teorizados e descobertos para serem naturalmente delineados e inter-relacionados." (LLOYD, 1995, p. 38). 
Como referido em trabalhos anteriores (GARCIA, 2001; 2009; 2010), os estudos avaliativos sobre a pesquisa educacional brasileira evidenciam, até a década de 1960, a hegemonia de modelos derivados da Psicologia, caracterizados como modelos experimentais que buscam as relações entre processos de ensino e seus produtos. No entanto, a partir da década de 1970, ainda no contexto da Ditadura Militar (1964-1984), as pesquisas passaram a incorporar - no espaço possível, por efeito do autoritarismo - os debates sociológicos derivados das teorias chamadas genericamente de reprodutivistas.

A análise das situações educativas, incluindo-se aquelas relacionadas ao ensino de conteúdos específicos, procurou sustentação nas macroteorias e, para além das explicações de natureza psicológica, foram construídas novas explicações sobre o fracasso escolar a partir da sociologia. A escola, enquanto instituição, passou a ser entendida como espaço de reprodução das desigualdades sociais, que acentua a distância entre as classes trabalhadoras e a cultura - na verdade, uma certa cultura que é privilegiada pela escolarização.

A contribuição da Sociologia, portanto, não pode ser negada; mas tratase de determinada perspectiva sociológica. A presença do conceito de cultura, pela teoria da reprodução cultural e social ou pela teoria do conflito cultural, permitiu deslocar o olhar dos pesquisadores educacionais para outros elementos que poderiam explicar, por exemplo, problemas de aprendizagem e evasão escolar de um número significativo de alunos das escolas públicas brasileiras. Para além das diferenças individuais, de características genéticas ou ainda de comportamentos desviantes, passou-se a focalizar atenção sobre as formas de construção simbólica presentes nas relações entre professores e alunos, as quais definem parte das condições de ensino. No caso brasileiro, ainda segundo Garcia (2009), a perspectiva antropológica começou a ganhar força na segunda metade da década de 1980, trazendo ao debate novos temas e novas opções teórico-metodológicas. Defendendo-se o conceito de sala de aula como cultura, anunciava-se a potencialidade do olhar antropológico para compreender os "processos associados à vida na sala de aula, a partir da presença do pesquisador em campo e levando em conta o que as pessoas fazem, bem como suas intenções". (DELAMONT; HAMILTON, 1991, p. 393).

Mas se a incorporação do conceito de cultura às pesquisas produziu, em dado momento, contribuições para explicar diferenças, conflitos e exclusões, também contribuiu para evidenciar que as complexas dinâmicas culturais produzidas entre os sujeitos na cotidianidade da escola não resultam de um sistema simbólico coerente e delimitado. Foi necessário admitir uma pluralidade no interior de cada grupo social e a existência de uma relação dinâmica entre sujeitos e culturas. (ROCKWELL, 1997). 
A difusão das abordagens etnográficas, no Brasil, pode ser fortemente relacionada aos trabalhos de Elsie Rockwell e outros pesquisadores ligados ao Departamento de Investigaciónes Educativas, do Centro de Investigaciónes y Estúdios Avanzados (México), influência que foi analisada por Garcia (2001)5. Segundo a autora, apesar de terem circulado no país, desde o final da década de 1970, diferentes vertentes de etnografia educacional, foi esse grupo que imprimiu as características que permaneceram na etnografia educacional produzida no Brasil nos anos subsequentes.

É preciso registrar que a etnografia chegou ao Brasil mesclando-se com outras perspectivas de estudo da realidade escolar, derivadas das teorias críticas e das diferentes formas de pesquisa-ação que circulavam no espaço acadêmico, o que causou certa dificuldade posterior para distinguir os diversos caminhos teórico-metodológicos em questão.

A partir de 1990, contudo, prevalece a etnografia sustentada, em sua origem, no conceito de cotidiano escolar de Agnes Heller e no caráter histórico das instituições sociais na perspectiva de Antonio Gramsci. A escola, entendida como construção social, pode ser apreendida pela pesquisa em seu movimento histórico, que se expressa na compreensão de que "a escola não é seguramente a mesma em todo o mundo capitalista, nem sequer nos países da América Latina." (EZPELETA; ROCKWELL, 1989, p. 11).

Segundo Garcia e Romanelli (2010), associando o olhar antropológico às análises sociológicas e históricas, nessa forma de compreender a etnografia educacional os estudos em escolas ganham força e sentido. Os autores emprestam a expressão da antropologia, referindo-se à ideia de que os antropólogos não estudam aldeias, mas em aldeias (GEERTZ, 2003, p. 33). Portanto, o estudo das práticas escolares implica a presença do pesquisador no espaço da escola não para coletar dados, mas para produzi-los a partir da observação e registro dos processos em estudo, no diálogo entre campo empírico e teoria. Deve-se ainda ressaltar que essas contribuições foram fortalecidas, no caso particular de pesquisas no âmbito da Linha de Pesquisa Cultura, Escola e Ensino, pela opção de não tratar restritamente os processos culturais como sistemas simbólicos, nem conceber o processo de investigação como interpretação de significados, como em vertentes fenomenológicas. As contribuições de Raymond Willliams e de Edward Thompson foram incorporadas de forma a inserir em outra vertente epistemológica o debate conceitual sobre as relações entre cultura, escola, sociedade e Estado. (GARCIA, 2001; GARCIA; ROMANELLI, 2010).

${ }^{5}$ Tese defendida na Universidade de São Paulo, sob orientação da Dra. Belmira Amélia de Oliveira Bueno. 
Portanto, tais questões evidenciam como os elementos do debate sociológico e antropológico marcaram o pensamento educacional nos últimos 30 anos no Brasil e definiram formas de compreender a pesquisa no campo de educação, em especial a que se volta ao estudo da escolarização, no âmbito das práticas escolares e, particularmente, da Didática. Trata-se de uma trajetória que, com origens na Psicologia, na década de 1960, vai transformando a pesquisa sob o efeito dos debates sociológicos e antropológicos que, ao final dos anos 1990, permitem configurar uma compreensão das situações educativas e didá-ticas no entrecruzamento de diferentes conhecimentos das Ciências Humanas.

Do diálogo com a Sociologia e a Antropologia, nas vertentes indicadas, decorrem algumas consequências para a pesquisa que se ocupa da escolarização e dos processos de ensino e aprendizagem, em especial quanto às situações didáticas:

a) opção privilegiada por estudos empíricos, na escola e nas aulas; b) a centralidade do conceito de cultura para compreender a reprodução e a produção de relações na experiência escolar;

c) a compreensão das práticas escolares como resultantes dos embates entre as normas oficiais e a vida cotidiana, âmbito em que os sujeitos reproduzem e também produzem, transformando a experiência escolar;

d) a necessidade de produzir/usar categorias analíticas que possibilitem captar particularidades - "as malhas finas" que o pesquisador utiliza para examinar a empiria;

e) as observações e as entrevistas como estratégias privilegiadas para aproximação com professores e alunos, sem excluir a análise documental;

f) entendimento do cotidiano escolar apenas como um primeiro nível de análise, a partir do qual podem ser atribuídos sentidos históricos às práticas presentes atualmente nas escolas.

Essa concepção de "pesquisa qualitativa" - ainda que constitua o eixo a partir do qual se desenvolvem os Seminários de Pesquisa - tem sido apropriada de diferentes formas pelos grupos temáticos da Linha Cultura, Escola e Ensino, a partir das abordagens teóricas e dos objetos privilegiados pelos pesquisadores, seus colaboradores e alunos. Em consequência, novas sistematizações têm sido permanentemente exigidas para responder à necessidade de construção dos objetos científicos. Em particular, serão destacados a seguir alguns elementos relativos aos desafios enfrentados em um grupo temático específico, que investiga os processos de ensino e aprendizagem da História. 


\section{Questões teórico-metodológicas para a investigação em Didática da His- tória}

A constituição e a consolidação, na última década, do Laboratório de Pesquisa em Educação Histórica ${ }^{6}$, na Universidade Federal do Paraná, possibilitou a articulação de um conjunto significativo de estudos cujo objetivo consiste em aproximar-se dos sujeitos, no espaço da escola, para compreender uma dimensão específica da experiência escolar relacionada à aprendizagem histórica. A atenção focalizada nos processos de ensino e aprendizagem de uma disciplina curricular específica - a História - exigiu reconfigurações no espectro teórico e metodológico das pesquisas.

É preciso lembrar que as investigações sobre o ensino têm sido avaliadas desde a década de 1960. Em estudo avaliativo realizado por Shulman (1997), foram considerados como elementos fundamentais nesse campo as capacidades, ações e pensamentos de alunos e professores e as pesquisas sobre ensino foram relacionadas por ele a quatro programas, três dos quais sustentados na Psicologia: a) em torno do modelo processo-produto; b) em torno dos processos cognitivos no espaço da aula; c) sobre a cognição do professor e a tomada de decisões na aula.

O quarto programa identificado pelo autor agrupa estudos sustentados na antropologia, sociologia e sociolinguística, associados à ecologia da sala de aula. Evidencia-se aqui um interesse específico por esse grupo pelas contribuições quanto ao entendimento de "que as salas de aula são espaços organizados social e culturalmente" e por "abrir espaço ao entendimento de que os resultados dos processos de aprendizagem devem ser examinados como produto de ações sociais, de processos em que os conhecimentos são objeto da construção simbólica entre sujeitos e grupos" (GARCIA, 2009, p. 95).

A presença marcante da Psicologia, inclusive em estudos mais recentes sobre o pensamento dos professores, produziu a aproximação dos pesquisadores com a sala de aula; mas, segundo Garcia (2009, p. 90), "isso não significou uma aproximação, na mesma medida, com o processo de ensino e de aprendizagem nas suas dimensões didático-metodológicas". No caso particular do ensino de História, a presença da Psicologia também influenciou a pesquisa - e ainda permanece presente - em especial quanto ao pensamento e à cognição dos alunos com relação à temporalidade, a partir das perspectivas piagetianas e sociointeracionistas.

Na década de 1990, no âmbito da Didática Geral e da Metodologia do Ensino de História, temas relativos ao uso de metodologias específicas e de di-

${ }^{6}$ Sobre o grupo e suas atividades, ver: $<$ http://www.lapeduh.ufpr.br $>$. 
ferentes linguagens, bem como sobre currículo e formação de professores, estabeleceram avanços significativos e reconhecidos - parte deles a partir do conceito de transposição didática. À recuperação do espaço da História como disciplina escolar, consolidado nos programas e currículos oficiais brasileiros a partir da década de 1980, após o final da Ditadura Militar, correspondeu, portanto, uma expansão do campo de pesquisa em Ensino de História, evidenciada nos eventos e publicações sobre o tema.

Mas deve-se destacar que, nesse campo, incluem-se pesquisas que relacionam História e Ensino de diferentes formas. Em levantamentos realizados por Evangelista e Triches (2006) e por Garcia (2009), nos grupos registrados no Conselho Nacional de Desenvolvimento Científico e Tecnológico (CNPq), ficou evidenciada a predominância de linhas de pesquisa que estudam a história do ensino de História sobre as linhas que estudam os processos de ensino e aprendizagem de História.

Referir-se, então, à pesquisa no ensino de História é considerar a existência de "um conjunto de trabalhos com inúmeros enfoques e abordagens, mas antes de tudo, com diferentes objetos de investigação que nem sempre podem ser identificados estritamente como estudo dos processos de ensino e aprendizagem numa perspectiva didático-metodológica”. (GARCIA, 2009, p. 83). Tratase de um campo diversificado, seja do ponto de vista epistemológico ou metodológico.

Nas duas últimas décadas, sem negar as contribuições possíveis no âmbito da Psicologia, muitas pesquisas sobre/na sala de aula passaram a ser realizadas no âmbito das disciplinas específicas - como a História, a Física, a Matemática. Os pesquisadores identificados com essa perspectiva buscam articular cada uma das ciências de referência com a educação e especialmente com o ensino, fortalecendo as Didáticas Específicas como um campo disciplinar e, portanto, de pesquisa.

Nessa direção é que se constituiu e consolidou, no Brasil, a perspectiva da Educação Histórica a partir do diálogo com pesquisadores de outros países, em especial Portugal e Inglaterra. Entre outras contribuições, essa perspectiva apontou a necessidade de pensar a Didática da História e a pesquisa sobre a aprendizagem em História a partir de elementos da própria História. Pode-se dizer que

Uma das linhas mais frutuosas desta pesquisa [em Educação Histórica] visa compreender as ideias de crianças e jovens na perspectiva (confirmada por vários estudos essencialmente qualitativos) de que é possível a construção de ideias históricas gradualmente mais sofisticadas, no que respeita à natureza do conhecimento histórico. (SCHMIDT; BARCA; GARCIA, 2010). 
Além disso, também interessa à pesquisa conhecer como os alunos usam a História para sua orientação temporal e, aqui, a contribuição veio particularmente de Rüsen, com a compreensão de que a consciência histórica se materializa na narrativa histórica. Dessa forma, a análise da narrativa de crianças e jovens permite ao pesquisador o acesso às formas pelas quais "o autor concebe o passado e utiliza suas fontes, bem como aos tipos de significância e sentidos de mudança que atribui à história". (SCHMIDT; BARCA; GARCIA, p. 12).

Estudos realizados no âmbito do LAPEDUH têm procurado esclarecer o sentido da Didática da História a partir dos trabalhos de Rüsen. A focalização das pesquisas nos processos pelos quais se aprende História, em situações de ensino, traz a necessidade de compreender tanto o conteúdo quanto as formas de organizar o trabalho didático, bem como as condições em que ele se realiza - o que se está denominando aqui de situação didática.

A estruturação teórico-metodológica na investigação de situações didáticas, neste caso no ensino e na aprendizagem da História, tem privilegiado alguns elementos derivados da confluência entre a Educação, a Antropologia e a Sociologia, com destaque aos seguintes:

a) são privilegiados estudos empíricos, desenvolvidos tanto para examinar processos nas escolas e/ou salas de aula ou materiais didáticos (destinados tanto aos professores como aos alunos), como manuais e propostas curriculares;

b) o investigador necessita, em casos específicos, produzir situações didáticas que permitam observar as ideias históricas de alunos, suas transformações sob interferência de ações de ensino e, portanto, que tipo de aprendizagem resulta;

c) a produção de dados é feita por meio de observações, entrevistas, questionários e outros instrumentos e também de análise documental. No caso dos professores, trata-se de conhecer suas ideias históricas, como concebem e se relacionam com o passado, como estruturam o ensino a partir de sua relação com o conhecimento histórico, que materiais utilizam em seu trabalho de preparação e desenvolvimento das aulas.

Considera-se, portanto, que a perspectiva da Educação Histórica permitiu configurar a pesquisa em Didática no âmbito da própria História e no diálogo com outras disciplinas das Ciências Humanas. Este foi um ponto de avanço na trajetória de pesquisa do grupo ligado ao LAPEDUH na última década, que abriu novos espaços de debate nos eventos específicos da área. Em especial, deve-se destacar a focalização na aprendizagem histórica e a importância 
atribuída à compreensão das narrativas no espaço da Educação Histórica formal, enquanto "meio imprescindível para as crianças e jovens exprimirem as suas compreensões do passado histórico e consciencializarem progressivamente a sua orientação temporal de forma historicamente situada." (SCHMIDT; BARCA; GARCIA, 2010, p. 12).

A revisão dos pressupostos teóricos e metodológicos para investigar os temas da Educação Histórica reafirmou a centralidade da própria História e apontou novos desafios que, certamente, deverão produzir transformações nas estratégias de investigação e, especialmente, na qualidade das análises das situações didáticas, na direção do que se apontará a seguir.

\section{Aproximações entre Antropologia e História: um diálogo em produção}

Da trajetória apresentada, pode-se depreender que se efetivou nas investigações sobre o ensino de História - com ampla influência em outros estudos produzidos na Linha de Pesquisa Cultura, Escola e Ensino - uma trajetória em que a pesquisa identificada genericamente como qualitativa ganhou configurações específicas.

A opção dos pesquisadores pelo estudo das relações entre indivíduo, sociedade e escolarização - que se desdobra em objetos específicos, tais como as relações entre sujeito e conhecimento - definiu desde logo a necessária aproximação com a Sociologia em determinadas perspectivas. Foram escolhidas aquelas que permitem olhar as práticas escolares como espaço de reprodução e produção social, bem como possibilitam tomar a cultura como ponto referencial para estudar a dimensão social da escola e do ensino - as sociologias da ação e a sociologia histórica.

Ficou evidenciado, também, o fértil diálogo com a Antropologia, pela centralidade do conceito de cultura e pela intenção de aproximação empírica com a escola e a sala de aula. A opção teórico-metodológica foi intensamente influenciada pela etnografia, em determinada perspectiva - particularmente apoiada no conceito de cotidiano (HELLER, 2002) e de escola como construção social (EZPELETA; ROCKWELL, 1989).

Assim, foi possível construir formas de investigar em escolas e em salas de aula, evidenciando-se que os diferentes objetos científicos são construídos a partir do diálogo entre o trabalho empírico e a necessária teorização sobre os processos em análise. A clareza da direção procurada não atenua as dificuldades na construção de tal possibilidade para estudar diferentes dimensões da experiência escolar e, em particular, a que diz respeito às relações entre os sujeitos e o conhecimento. 
Os desafios decorrentes dessas opções têm sido enfrentados de forma gradual e permanente em cada investigação realizada. Pode-se dizer que foram obtidos avanços que se referem a dois conjuntos interligados. O primeiro diz respeito a aspectos teórico-metodológicos, entre os quais se destacam as formas de acercar-se da escola ou sala de aula; a produção de instrumentos adequados para captar as relações entre os sujeitos e conhecimentos e para encontrar os significados culturais de determinadas ações; e as relações entre as determinações estruturais, as normas oficiais e a experiência dos sujeitos escolares. $\mathrm{O}$ segundo refere-se a aspectos éticos da pesquisa, como a busca por um maior grau de participação dos sujeitos na definição de informações a serem ou não incluídas nos relatórios científicos ou, ainda, a opção pela produção colaborativa de investigações.

No estágio atual do debate no âmbito dos seminários de pesquisa da Linha Cultura, Escola e Ensino - e particularmente nas investigações em Educação Histórica - problematizam-se a necessidade e as formas para recuperar a dimensão histórica dos processos em estudo. Se, do ponto de vista teórico, a compreensão sociológica e antropológica produziu avanços significativos na explicitação de determinadas relações, ainda é necessário avançar na apreensão da historicidade de tais processos.

Isto significa que é necessário buscar mais do que a compreensão sobre as ações intencionalmente voltadas ao ensino e sobre as condições nas quais se desenvolve o trabalho didático. As pesquisas devem debruçar-se sobre o conjunto de relações que uma situação didática mantém com outras, localizadas no mesmo tempo, para explicitar "quadros interativos, sempre pensados como múltiplos, particularizados pelo inventário de agentes e pelo teor das relações estabelecidas." (OLIVEIRA, 1999, p. 9).

Mas, além disso, é preciso avançar na compreensão e explicitação da "espessura histórica" (CARDOSO DE OLIVEIRA, 1999), que definiu condições pelas quais se constituíram determinados elementos presentes, hoje, na vida das escolas. Como se tem defendido, é preciso historicizar os processos estudados, mesmo em pesquisas sobre processos atuais e, portanto, que não estão sendo estudados no âmbito formal da História da Educação. Esse desafio tem sido colocado a partir do fortalecimento de abordagens que defendem a aproximação entre História e Antropologia.

Destacam-se, como estímulo ao debate, duas contribuições relevantes na produção das ideias aqui apresentadas. A primeira contribuição vem de reflexões feitas por Rockwell (2009) a respeito das aproximações possíveis entre a História e a Antropologia, apesar das diferenças no que se refere às formas de trabalhar dos historiadores e dos antropólogos. 
Para a autora, as duas disciplinas "têm trajetórias convergentes" e "atualmente, muitos antropólogos e etnólogos realizam estudos sobre épocas passadas" buscando "integrar a dimensão temporal ao trabalho antropológico". Por outro lado, os historiadores têm buscado "orientação nos textos teóricos da Antropologia para potencializar uma nova leitura dos documentos de arquivo e uma interpretação de outras fontes que deem conta da dimensão cultural" (ROCKWELL, 2009, p. 143).

Interessada em colocar em debate essa aproximação tendo em vista o estudo dos processos educativos, para Rockwell a questão de fundo estaria nos debates sobre o conceito de cultura, que resultaram em uma concepção de "cultura historizada" . Isso permitiu, segundo Rockwell, o desenvolvimento da Antropologia Histórica, que se agregou ao esforço dos historiadores que "procuram documentar as continuidades culturais em diversas regiões" (2009, p. 148). Os antropólogos, pelo seu lado, buscam "evidência das origens e transformações de configurações culturais atuais com leituras novidosas da documentação de arquivos, assim como com diversas fontes orais e gráficas." (2009, p. 149).

Citando autores como Sahlins (1985), Sider (1986), Oknuki-Tierney (1990), Fabian (1991) e Asad (2003), a autora aponta as possibilidades abertas para novas formas de estudar a dinâmica educativa a partir da aproximação entre História e Antropologia:

[...] sempre é possível captar uma variedade de vozes nos diferentes documentos que estudamos ou elaboramos, como propôs tão lucidamente Bakhtin (1982). Algumas vozes se complementam, outras se contrapõem, mas conseguem todas elas desvelarem algo, seja nesse mundo não documentado do passado ou nos interstícios dos nossos próprios entornos culturais. Tudo isso coloca exigências ao pesquisador, particularmente ao redigir um texto que possa integrar alguns dos múltiplos significados originados na fala e nas práticas. Estes textos encontrarão seu sentido se forem inseridos novamente em um diálogo, um diálogo ao longo do tempo, em que se apaguem as fronteiras entre a história e a antropologia, para iluminar melhor alguns dos processos educativos que temos vivido e que ainda viveremos. (ROCKWELL, 2009, p. 155-156).

A segunda contribuição, e também um estímulo ao debate, deriva da leitura de trabalhos de antropólogos brasileiros, em particular um dos textos produzidos por João Pacheco de Oliveira (1999). O autor escolhe, nessa obra, a "dimensão

${ }^{7}$ As citações dessa obra de Rockwell (2009) foram livremente traduzidas; neste caso, optou-se por manter essa expressão como apresentada no original, em espanhol. 
histórica" como "estratégia para uma reflexão sobre as sociedades e culturas indígenas do Brasil", recusando a "partição radical de saberes entre antropologia e história" e apresentando aos leitores um "exercício de antropologia histórica".

É relevante lembrar os riscos de transposição direta, para o estudo da escola, das construções feitas pelos antropólogos em outras "situações etnográficas" - entendidas como trabalho de campo, com todas as condições que envolvem produção dos dados etnográficos (OLIVEIRA, 199, p. 9). Inúmeros trabalhos foram produzidos na direção de esclarecer elementos distintivos e particularizadores da etnografia educacional (ERICKSON, 1984; EZPELETA; ROCKWELL, 1989, entre outros), com destaque a pelo menos dois elementos: boa parte da investigação ocorre em escolas localizadas nas sociedades contemporâneas; e os pesquisadores compartilham significados simbólicos com os sujeitos escolares, o que coloca questões ao "estranhamento" em relação à "cultura estudada"

As especificidades, contudo, não devem impedir a possibilidade de diálogo. Nesse sentido, e assumindo individualmente os riscos pela analogia construída, pode-se pensar em tomar os processos de ensino e aprendizagem escolar como "situações didáticas", que se constituiriam em objeto de pesquisa necessariamente situado na confluência dos conhecimentos educacionais especialmente da Didática-com os conhecimentos sociológicos, antropológicos e históricos. E, portanto, exigiria a incorporação de teorias e métodos dessas disciplinas para a construção científica de tal objeto, com toda a complexidade que isso possa significar.

Do ponto de vista do trabalho empírico, a situação didática deve "tomar a contemporaneidade como uma pressuposição fundadora", como acontece em uma situação etnográfica, na qual os sujeitos agem com finalidades múltiplas e complexas, partilhando de um mesmo tempo histórico (OLIVEIRA, 2009). Porém, na perspectiva aqui assumida, ela deve ser explicada em seu caráter heterogêneo, dinâmico e construído, portanto, também na perspectiva de uma situação histórica.

Assim, ao finalizar, enfatiza-se que ao abrir a possibilidade de estudar as situações didáticas como lugar de interseção de disciplinas como a Sociologia, a Antropologia e a História, postula-se também a possibilidade de olhar histórica, antropológica e sociologicamente o conjunto de elementos que configuram essa situação: o ensino - enquanto ação intencional que supõe escolhas de objetivos e finalidades, de conteúdos e prioridades, de estratégias, materiais, re-

${ }^{8} \mathrm{O}$ que também se aplica de forma geral à Antropologia, uma vez que as relações entre o pesquisador e seu objeto não podem mais ser descritas sob a ótica do exotismo e do estranhamento. (OLIVEIRA, 2009). 
cursos; a aprendizagem - como resultado, em grande medida, dessa ação, mas articulada com outras experiências dos sujeitos; e as condições nas quais essa ação se materializa - o espaço sociocultural e histórico em que se realiza a educação.

Com relação ao estudo da situação didática, é possível ampliar o olhar etnográfico sobre a diversidade de práticas que constituem a vida nas aulas, reconhecendo-a como uma construção que só ganha sentido quando historicizada - no tempo em que se manifestam e na sua "espessura histórica". É possível, inclusive, analisar etnograficamente os materiais empíricos que circulam e que circularam na cultura escolar, interpelando-os como fontes que ajudam a explicar as diferentes vozes que se expressam, naquele momento, no espaço escolar.

O diálogo com a Antropologia Histórica, no caso da Educação Histórica, consolida um percurso teórico e metodológico construído fundamentalmente a partir das obras de Rüsen. Nelas, destacam-se os conceitos de cultura histórica e consciência histórica que, com suas derivações, contribuem para a compreensão dos significados e formas da experiência com o conhecimento histórico, inclusive o que se ensina na escola.

Essa opção para o estudo das práticas escolares, na confluência entre a Didática, a História, a Antropologia e a Sociologia, corresponde, no fundo, à busca por um fundamento comum no campo das Ciências Humanas, que contribua para explicar a complexidade das situações em estudo "sem pontas soltas", como expressou Lloyd (1995, p. 230).

O contato - intenso, desafiador e prazeroso - com pesquisas que procuram explicar a vida das escolas e a produção das aulas, decorrentes das atividades da autora nos seminários de pesquisa e em bancas de mestrado e doutorado permite compartilhar a crença expressa de modo irretocável por Rockwell, ao descrever sua experiência como pesquisadora:

Resulta impensável, a partir desse enfoque, compreender situações e sucesso presenciados atualmente sem considerar a dimensão temporal. A experiência de campo nos confronta com a heterogeneidade; a investigação histórica permite situar a diversidade cotidiana em uma configuração inteligível, que esclarece a formação social das práticas e saberes observados. Por sua vez, a mirada antropológica sugere novas formas de indagar na história, de entender a temporalidade e de explorar os vestígios materiais e textuais. Integrar história e antropologia tem sido minha forma de assegurar, à evidência fragmentada que se recolhe no campo e no arquivo, uma articulação possível. (ROCKWELL, 2009, p. 14).

Dessa crença deriva a afirmação que dá sentido, em última instância, ao esforço de produção de conhecimento sobre a escola e, em especial, sobre o 
ensino. Também concordando com Rockwell (2009, p. 36), a perspectiva desejada para a pesquisa qualitativa aponta a possibilidade e - por que não? a esperança de que "se conhecermos a história das transformações das escolas, será possível criar outra escola".

\section{REFERÊNCIAS}

ATKINSON, P.; DELAMONT, S.; HAMMERSLEY, M. Qualitative research traditions; a British response to Jacob. Review of Educational Research, n. 58, p. 231-250, 1988.

CARDOSO DE OLIVEIRA, Roberto. Prefácio. In: OLIVEIRA, João Pacheco de. Ensaios em Antropologia Histórica. Rio de Janeiro: Editora UFRJ, 1999. p. 11-18.

DELAMONT, Sara; HAMILTON, David. A pesquisa em sala de aula: uma crítica e uma nova abordagem. In: PATTO, M. (Org.). Introdução à Psicologia Escolar. 2. ed. São Paulo: T. A. Queiroz Editor, 1991. p. 378-398.

ERICKSON, Frederick. What makes school ethnography 'ethnographic'? Anthropology and Education Quarterly, v. 15, n. 1, p. 51-66, 1984.

EVANGELISTA, Olinda; TRICHES, Jocemara. Ensino de História, Didática da História, Educação Histórica: alguns dados de pesquisa (2000-2005). Educar, Curitiba, Editora UFPR, Especial, p. 33-55, 2006.

EZPELETA, J.; ROCKWELL, E. Pesquisa participante. Trad. Francisco S. de Alencar Barbosa. 2. ed. São Paulo: Cortez: Editores Associados, 1989.

GARCIA, Tânia Maria F. Braga. Origens e questões da etnografia educacional no Brasil: um balanço de teses e dissertações (1981-1998). Tese (Doutorado em Educação) - FEUSP. 308 p. São Paulo, 2001.

. Relações entre ensino e aprendizagem histórica: desafios para a pesquisa em Educação. In: SCHMIDT, M. A.; BARCA, I. (Orgs.). Aprender História: perspectivas da Educação Histórica. Ijuí: Ed. Unijuí, 2009. p. 77-116.

. Cotidiano escolar, pesquisa e formação docente. In: ENS, R.; BEHRENS, M. (Org.). Formação do professor: profissionalidade, pesquisa e cultura escolar. 1. ed. Curitiba: Champagnat, 2010. p. 167-184. (Coleção Formação do Professor, v. 1). 
; ROMANELLI, Guilherme G. L. Potencialidades da etnografia educativa para produzir conhecimento sobre os processos escolares: questões a partir de estudos sobre avaliação e sobre música na escola. Revista Europea de Etnografía de la Educación, v. 7/8, p. 261-271, 2010.

GEERTZ, Clifford. La interpretación de las culturas. Trad. Alberto Bixio. Barcelona: Editorial Gedisa, 2003, p. 33.)

HAMMERSLEY, Martyn. What's Wrong With Ethnography? Methodological explorations. London: Routledge, 1992.

HELLER, Agnes. Sociología de la vida cotidiana. Trad. José Francisco Ivars e Enric Pérez Nadal. Barcelona: Península, 2002.

JACOB, Evelyn. Qualitative research traditions: a review. Review of Educational Research, n. 57, p. 1-50, 1987.

LLOYD, Christopher. As estruturas da História. Trad. Maria Júlia Goldwasser. Rio de Janeiro: Zahar, 1995.

MARTINS, Estevão de R. Historicidade e consciência histórica. In: SCHMIDT, M. A.; BARCA, I.; MARTINS, E. (Orgs.). Jörn Rüsen e o ensino de história. Curitiba: Ed. UFPR, 2010. p. 7-10.

OLIVEIRA, João Pacheco de. Ensaios em Antropologia Histórica. Rio de Janeiro: Editora UFRJ, 1999.

. Pluralizando tradições etnográficas. Cadernos do LEME, Campina Grande, v. 1, n. 1, p. 2-27, jan./jun. 2009.

ROCKWELL, Elsie. De huellas, bardas y veredas: una historia cotidiana en la escuela. In: . (Coord.). La escuela cotidiana. México: Fondo de Cultura Económica, 1995.

. La dinamica cultural en la escuela. In: ALVAREZ, Amélia (Ed.). Hacia un curriculum cultural: la vigencia de Vygotski en la educación. Madrid: Fundación Infancia y Aprendizaje, 1997.

. La experiencia etnográfica: historia y cultura en los procesos educativos. 1. ed. Buenos Aires: Paidós, 2009.

RÜSEN, Jörn. El desarrollo de la competencia narrativa en el aprendizaje histórico. Una hipótesis ontogenética relativa a la conciencia moral. Trad. Silvia Finocchio. Propuesta Educativa, Argentina, n.7, p. 27-37, out. 1992. 
. Razão histórica: teoria da história: fundamentos da ciência histórica. Tradução de Estevão de Rezende Martins. Brasília: Editora da Universidade de Brasília, 2001a.

. História viva: teoria da história: formas e funções do conhecimento histórico. Tradução de Estevão de Rezende Martins. Brasília: Editora da Universidade de Brasília, 2001b.

SCHMIDT, Maria Auxiliadora; GARCIA, Tânia Maria F. Braga. História e Educação: diálogos em construção In: ; HORN, G. B. (Orgs.). Diálogos e perspectivas de investigação. 1. ed. Ijuí: Unijuí, v. 1, p. 29-48, 2008 .

; BARCA, I.; GARCIA, Tânia Maria F. Braga. Significados do pensamento de Jörn Rüsen para investigações na área da educação histórica. In: ; MARTINS, E. (Orgs.). Jörn Rüsen e o ensino de História. Curitiba: Ed. UFPR, 2010. p. 11-21.

SHULMAN, Lee. Paradigmas y programas de investigación en el estudio de la enseñanza: una perspectiva contemporánea. In: WITTROCK, Merlin (Comp.). La investigación de la enseñanza, I: enfoques, teorías y métodos. Barcelona: Paidós, 1997. p. 9-91.

THOMPSON, E. P. A miséria da teoria ou um planetário de erros: uma crítica ao pensamento de Althusser. Rio de Janeiro: Zahar, 1981.

WILLIAMS, Raymond. La larga revolución. Buenos Aires: Nueva Visión, 2003.

Texto recebido em 13 de março de 2011.

Texto aprovado em 20 de setembro de 2011. 
